\title{
ASPECTS REGARDING THE COGNITIVE TRAINING OF HIGH-PERFORMANCE FOOTBALL PLAYERS
}

\author{
Marius STOICA ${ }^{1}$, Cornel BLEJAN ${ }^{1}$, Adina DREVE ${ }^{*}$ \\ ${ }^{1}$ National University of Physical Education and Sport, Faculty of Physical Education and Sport, Bucharest, Romania \\ *Corresponding author: adina_dreve@yahoo.com
}

DOI: $10.35189 /$ iphm.icpesk.2019.45

\begin{abstract}
The game of football is a multidisciplinary sport, so it requires input from a variety of areas and a range of specialists. Cognitive training provides the opportunity to have fun and motivating exercises that help improve both physical fitness and cognitive potential. An important part of these cognitive exercises involve the cognitive system of the player and how these means can be modelled by simulating the movements specific to each sport discipline, which are individualised according to each player's position and skills. In this study, we aim to present both the cognitive training we have designed individually for the football game and its benefits. This physical training involves a $3 D$ environment with multiple moving or static objects that lead to the improvement of cognitive abilities to stimulate neuroplasticity. Cognitive training involves and improves working memory, attention, short-term memory, concentration, the speed of transmission and processing of visual information and, last but not least, improves awareness. The objective of this study is to monitor the evolution of athlete training in the cognitive room compared to athletes who do this type of training. The study involves two groups that have previously performed a cognitive test, after which one group is trained on land, and the other is trained in the cognitive room. Finally, both groups will be tested to track the changes.
\end{abstract}

Keywords: cognitive training, football, high performance, working memory, cognitive room.

\section{Introduction}

Today's sport in general and football in particular require physically and cognitively prepared athletes. Physical demands in football differ from one game to another, from one opponent to another and impose certain positions and situations that can block the athlete (Dellal, 2008).

Therefore, it is important for the football player to be able to decode all the information that the opponent requires and to respond as quickly as possible to cognitive perceptions imposed by the environment or contextual playing situation.

Players must use the accumulated information and experience to anticipate each opponent's action to make the best choices for their team.

Numerous scientific studies have shown that brain stimulation during exercise leads to the generation of new neural connections, increasing the individual's ability to focus and concentration. In sports games such as football, some cognitive skills are needed, such as anticipating situations, evaluating the situation, making the right decision as quickly as possible (Johnson \& Raab, 2003).

Cognitive training improves physical and sensory abilities, stimulates muscles and cognitive areas. It takes time to reach a state of maximum concentration, simple and distributive attention and improve the other indispensable qualities in sport (Lorains, Ball, \& MacMahon, 2013).

The brain is the main command centre that coordinates all actions of the human body. The way it works affects the athlete's motor control, concentration, reaction speed, physical and mental restoration, etc.

Recent studies report that there are two different areas of intelligence: crystalline and fluid. Crystal intelligence refers to the ability to store and remember information, as well as to process, analyse and evaluate information in real time. (Ward \& Williams, 2003)

We present some of the benefits of using this training to prepare athletes: faster information processing, improving attention and focusing on key moments, managing critical situations in important situations, improving techniques in stress situations, making quick optimal decisions under pressure and, last but not least, improving the skills specific to a sport discipline.

\section{Research subjects and stages}

The subjects are members of the "Universitatea Craiova" Senior Football Team. They are 22 in number, two per position, and are divided into two groups. The research was conducted over a six-week period during which the experiment group had two cognitive-room training sessions per week, and the control group had two land workouts per week respecting the same technical objectives. Two tests were performed: initial testing (before starting the training) and final testing (six weeks later). 


\section{Research hypothesis}

In this research, we start from the hypothesis that the inclusion of cognitive training in the game of football improves the ability of players to anticipate, inform and evaluate existing situations and play patterns.

\section{Material and Methods}

\section{Description of the ball triangle cognitive test}

Cognitive objectives:

- Selective attention (wall-mounted figures = permanent viewing of the position of teammates and opponents on the field)

- Distressing attention (rebounder and ball balloons = teammate asking for the ball or pass)

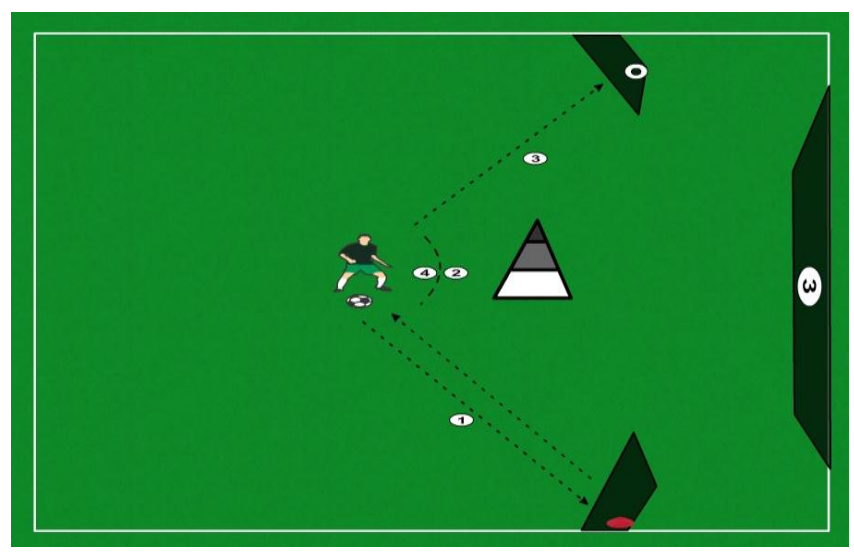

Figure 1. Description of the test applied

Description:

A light sensor is attached to each rebounder, and random numbers are played on the projector that changes every second. The player must strike the rebounder with the ball on which the sensor has lit (1), taking the direction in which it is to be moved (2), hitting the rebounder that has turned on (3) orientated control (4). The player continuously writes the figures that are permanently prompted on the wall, ensuring that he keeps on getting informed, and whenever he drops his head he loses a figure. When the player hits the ball with a rebounder whose led has turned on, it goes off. The player must "clear" 20 LEDs as soon as possible and must not miss out of the visual field figures projected on the wall that change at a 2-second interval. (Figure 1)

The test starts when the player's pulse reaches 80 beats per minute (bpm).

In addition to cognitive work, the following components are also improved:

Technical: step, take-over, directional control, step intensity (ball sense)

Tactical: opening the playing angles and positioning according to the ball

Physical: engaging all motion planes and engaging specific motion paths.

\section{Results}

The tables below show the data obtained in the initial and final tests by the control group and the experimental group.

Table 1 presents the results obtained in the initial test by the experiment group. Thus, the subjects had a minimum value of 41.38 seconds and a maximum of 45.83 seconds; minimum heart rate was $170 \mathrm{bpm}$ and maximum heart rate was $181 \mathrm{bpm}$. Missed LEDs have a minimum value of 0 and a maximum of 3 , and missed figures have a minimum value of 3 and a maximum of 6 . 
International Proceedings of Human Motricity/ ICPESK 2019

Supplementary Issue of Discobolul - Physical Education, Sport and Kinetotherapy Journal, 2019

Table 1. Results obtained in the initial test by the experiment group

\begin{tabular}{|c|c|c|c|c|c|c|}
\hline No. & Position & $\begin{array}{c}\text { Time achieved } \\
(\mathrm{sec})\end{array}$ & HR min & HR max & $\begin{array}{c}\text { Missed } \\
\text { lights }\end{array}$ & $\begin{array}{l}\text { Missed } \\
\text { numbers }\end{array}$ \\
\hline 1 & Goalkeeper & $45 " 83$ & 80 & 173 & 1 & 4 \\
\hline 2 & Right Full-back & $44 ” 75$ & 80 & 175 & 2 & 4 \\
\hline 3 & Centre-back & $43 ” 17$ & 80 & 177 & 3 & 5 \\
\hline 4 & Centre-back & $43 ” 22$ & 80 & 171 & 2 & 4 \\
\hline 5 & Left Full-back & $44 ” 08$ & 80 & 178 & 0 & 5 \\
\hline 6 & Right Wide midfield & $43 ” 75$ & 80 & 180 & 1 & 3 \\
\hline 7 & Defensive midfield & $42 ” 93$ & 80 & 179 & 2 & 4 \\
\hline 8 & Right Attacking midfield & $41 ” 54$ & 80 & 172 & 2 & 4 \\
\hline 9 & Left Attacking midfield & $42 ” 61$ & 80 & 170 & 1 & 5 \\
\hline 10 & Left Wide midfield & $41 ” 38$ & 80 & 177 & 1 & 4 \\
\hline 11 & Centre forward & $42 ” 32$ & 80 & 181 & 0 & 6 \\
\hline \multicolumn{7}{|c|}{ Statistical analysis } \\
\hline \multicolumn{2}{|c|}{ Minimum value } & 41.38 & 80 & 170 & 0 & 3 \\
\hline \multicolumn{2}{|c|}{ Maximum value } & 45.83 & 80 & 181 & 3 & 6 \\
\hline \multicolumn{2}{|c|}{ Difference } & 4.45 & 0 & 11 & 3 & 3 \\
\hline
\end{tabular}

In the initial test, the control group had a minimum time of 40.19 seconds and a maximum of 44.03 seconds; minimum heart rate was $161 \mathrm{bpm}$ and maximum heart rate was $170 \mathrm{bpm}$. Missed LEDs have a minimum value of 0 and a maximum of 1 , and missed figures have a minimum value of 0 and a maximum of 1 . The test results are shown in Table 2.

Table 2. Results obtained in the initial test by the control group

\begin{tabular}{llccccc}
\hline No. & \multicolumn{1}{c}{ Position } & $\begin{array}{c}\text { Time achieved } \\
(\mathrm{sec})\end{array}$ & HR min & HR max & $\begin{array}{c}\text { Missed } \\
\text { lights }\end{array}$ & $\begin{array}{c}\text { Missed } \\
\text { numbers }\end{array}$ \\
\hline 1 & Goalkeeper & $44 " 03$ & 80 & $80-168$ & 0 & 1 \\
2 & Right Full-back & $43 " 24$ & 80 & $80-169$ & 0 & 0 \\
3 & Centre-back & $42 " 09$ & 80 & $80-167$ & 1 & 1 \\
4 & Centre-back & $42 " 18$ & 80 & $80-161$ & 0 & 1 \\
5 & Left Full-back & $42 " 99$ & 80 & $80-169$ & 0 & 1 \\
6 & Right Wide midfield & $42 " 15$ & 80 & $80-168$ & 0 & 0 \\
7 & Defensive midfield & $41 " 50$ & 80 & $80-165$ & 0 & 0 \\
8 & Right Attacking midfield & $40 " 23$ & 80 & $80-164$ & 0 & 1 \\
9 & Left Attacking midfield & $41 " 52$ & 80 & $80-161$ & 0 & 1 \\
10 & Left Wide midfield & $40 " 19$ & 80 & $80-168$ & 0 & 0 \\
11 & Centre forward & $40 " 99$ & 80 & $80-170$ & 0 & 1 \\
\multicolumn{2}{l}{ Minimum value } & Statistical analysis & & & \\
Maximum value & 40.19 & 80 & 161 & 0 & 0 \\
Difference & 44.03 & 80 & 170 & 1 & 1 \\
\hline
\end{tabular}

As shown in Table 3, the experimental group obtained in the final test a minimum time of 41.54 seconds and a maximum of 45.23 seconds; minimum heart rate was $172 \mathrm{bpm}$, and maximum heart rate value was $180 \mathrm{bpm}$. Missed LEDs have a minimum value of 0 and a maximum of 3, and missed figures have a minimum value of 3 and a maximum of 6 . 
International Proceedings of Human Motricity/ ICPESK 2019

Supplementary Issue of Discobolul - Physical Education, Sport and Kinetotherapy Journal, 2019

Table 3. Results obtained in the final test by the group experiment

\begin{tabular}{|c|c|c|c|c|c|c|}
\hline No. & Position & $\begin{array}{c}\text { Time achieved } \\
(\mathrm{sec})\end{array}$ & HR min & HR max & $\begin{array}{c}\text { Missed } \\
\text { lights }\end{array}$ & $\begin{array}{c}\text { Missed } \\
\text { numbers }\end{array}$ \\
\hline 1 & Goalkeeper & $45 ” 23$ & 80 & 178 & 2 & 3 \\
\hline 2 & Right Full-back & $45 ” 02$ & 80 & 179 & 2 & 5 \\
\hline 3 & Centre-back & $43 ” 47$ & 80 & 172 & 3 & 5 \\
\hline 4 & Centre-back & $42 ” 92$ & 80 & 175 & 2 & 3 \\
\hline 5 & Left Full-back & $44 ” 21$ & 80 & 176 & 1 & 5 \\
\hline 6 & Right Wide midfield & $43 ” 18$ & 80 & 175 & 1 & 4 \\
\hline 7 & Defensive midfield & $43 " 12$ & 80 & 173 & 2 & 3 \\
\hline 8 & Right Attacking midfield & $41 " 64$ & 80 & 176 & 2 & 5 \\
\hline 9 & Left Attacking midfield & $41 ” 98$ & 80 & 176 & 1 & 3 \\
\hline 10 & Left Wide midfield & $41 ” 54$ & 80 & 179 & 1 & 5 \\
\hline 11 & Centre forward & $42 ” 32$ & 80 & 180 & 0 & 6 \\
\hline \multicolumn{7}{|c|}{ Statistical analysis } \\
\hline \multicolumn{2}{|c|}{ Minimum value } & 41.54 & 80 & 172 & 0 & 3 \\
\hline \multicolumn{2}{|c|}{ Maximum value } & 45.23 & 80 & 180 & 3 & 6 \\
\hline \multicolumn{2}{|c|}{ Difference } & 3.60 & 0 & 8 & 3 & 3 \\
\hline
\end{tabular}

The control group obtained in the final test a minimum time of 41.20 seconds and a maximum of 45.03 seconds; minimum heart rate was $189 \mathrm{bpm}$, and maximum heart rate was $178 \mathrm{bpm}$. Missed LEDs have a minimum value of 0 and a maximum of 2, and missed figures have a minimum value of 1 and a maximum of 4 . The results are shown in Table 4.

Table 4. Results obtained in the final test by the group control

\begin{tabular}{|c|c|c|c|c|c|c|}
\hline No. & Position & $\begin{array}{l}\text { Time achieved } \\
(\mathrm{sec})\end{array}$ & $\mathrm{HR}$ min & $\mathrm{HR}$ max & $\begin{array}{l}\text { Missed } \\
\text { lights }\end{array}$ & $\begin{array}{c}\text { Missed } \\
\text { numbers }\end{array}$ \\
\hline 1 & Goalkeeper & $45 ” 03$ & 80 & 175 & 2 & 3 \\
\hline 2 & Right Full-back & $44 ” 88$ & 80 & 171 & 1 & 2 \\
\hline 3 & Centre-back & $43 ” 19$ & 80 & 170 & 1 & 3 \\
\hline 4 & Centre-back & $42 " 54$ & 80 & 170 & 1 & 1 \\
\hline 5 & Left Full-back & $44 ” 01$ & 80 & 169 & 0 & 4 \\
\hline 6 & Right Wide midfield & $42 ” 91$ & 80 & 172 & 1 & 2 \\
\hline 7 & Defensive midfield & $42 ” 86$ & 80 & 169 & 1 & 1 \\
\hline 8 & Right Attacking midfield & $41 ” 33$ & 80 & 174 & 2 & 2 \\
\hline 9 & Left Attacking midfield & $41 ” 77$ & 80 & 171 & 1 & 2 \\
\hline 10 & Left Wide midfield & $41 ” 20$ & 80 & 176 & 1 & 1 \\
\hline 11 & Centre forward & $41 ” 98$ & 80 & 178 & 0 & 2 \\
\hline \multicolumn{7}{|c|}{ Statistical analysis } \\
\hline \multicolumn{2}{|c|}{ Minimum value } & 41.20 & 80 & 169 & 0 & 1 \\
\hline \multicolumn{2}{|c|}{ Maximum value } & 45.03 & 80 & 178 & 2 & 4 \\
\hline \multicolumn{2}{|c|}{ Difference } & 3.83 & 0 & 9 & 2 & 3 \\
\hline
\end{tabular}

The statistical interpretation (Popa, 2008) shows that the mean time in the initial testing is lower for the control group (43.14 sec) compared to the experiment group $(43.23 \mathrm{sec})$, while in the final testing, the experiment group has a time value of $41.91 \mathrm{sec}$, and the control group, a time value of $42.88 \mathrm{sec}$ (Table 5). The value of the coefficient of variation reveals that the group has low scattering, the mean being representative for all tests in both groups. 
International Proceedings of Human Motricity/ ICPESK 2019

Supplementary Issue of Discobolul - Physical Education, Sport and Kinetotherapy Journal, 2019

Table 5. Statistical results in the initial test (IT) and final test (FT) for the experiment group (EG) and control group $(C G)$

\begin{tabular}{|c|c|c|c|c|c|c|}
\hline \multirow[t]{2}{*}{ Statistical tests } & \multicolumn{2}{|c|}{ Arithmetic mean } & \multicolumn{2}{|c|}{ Standard deviation } & \multicolumn{2}{|c|}{ Coefficient of variation } \\
\hline & IT & FT & IT & FT & IT & FT \\
\hline Time achieved (EG) & $43 ” 23$ & $41 " 91$ & 1.32 & 1.20 & 3.05 & 2.86 \\
\hline Time achieved (CG) & $43 ” 14$ & 42.88 & 1.26 & 1.31 & 2.92 & 3.05 \\
\hline $\mathrm{HR} \max (\mathrm{EG})$ & 175.72 & 166.36 & 3.77 & 3.17 & 2.14 & 1.90 \\
\hline HR max (CG) & 176.27 & 172.27 & 2.53 & 3.03 & 1.43 & 1.75 \\
\hline Missed lights (EG) & 1.36 & 0,09 & 0.92 & 0.30 & 67.64 & 333.33 \\
\hline Missed lights (CG) & 1.54 & 1 & 0.82 & 0.63 & 53.24 & 63 \\
\hline Missing numbers (EG) & 4.36 & 0.63 & 0.80 & 0.50 & 18.34 & 79.36 \\
\hline Missing numbers (CG) & 4.27 & 2.09 & 1.10 & 0.94 & 25.76 & 44.97 \\
\hline
\end{tabular}

In terms of heart rate, the average time in the initial test for the experiment group was $175.72 \mathrm{bpm}$, while the control group recorded an average value of $176.27 \mathrm{bpm}$; in the final test, the experiment group had $166.36 \mathrm{bpm}$, and the control group, $172.27 \mathrm{bpm}$. The value of the coefficient of variation reveals that the group has low scattering, the mean being representative for all tests in both groups.

Regarding the value of missed faults in the test, the experiment group obtained a 1.36 LED value in the initial test, while the control group obtained a value of 1.54. In the final test, the average value was 0.09 LEDs for the experiment group, while the control group had a value of 1 . The value of the coefficient of variation reveals that the scattering is high and the average has low representativeness in both tests of the two groups.

In the initial test, the number of missed figures was 4.36 for the experiment group, and for the control group, 4.27; in the final test, the experiment group had a value of 0.63 , and the control group obtained 2.09. The value of the coefficient of variation reveals that the scattering is large and the average has low representativeness in both tests of the two groups, except for the initial testing of both groups, where the scattering is medium, and the average is sufficiently representative. (Figure 2)

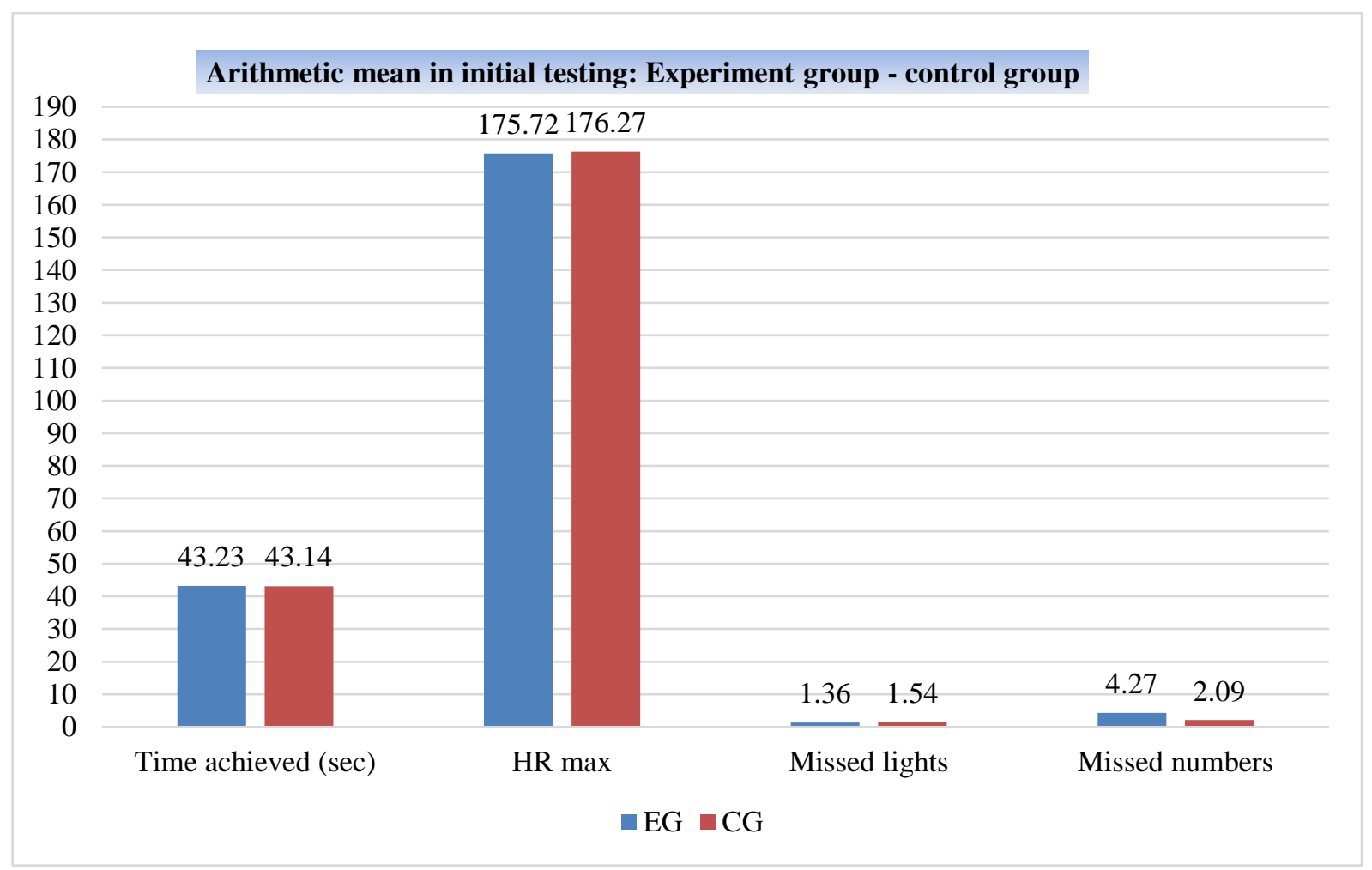

Figure 2. Average results in the initial test - Experiment and control groups 


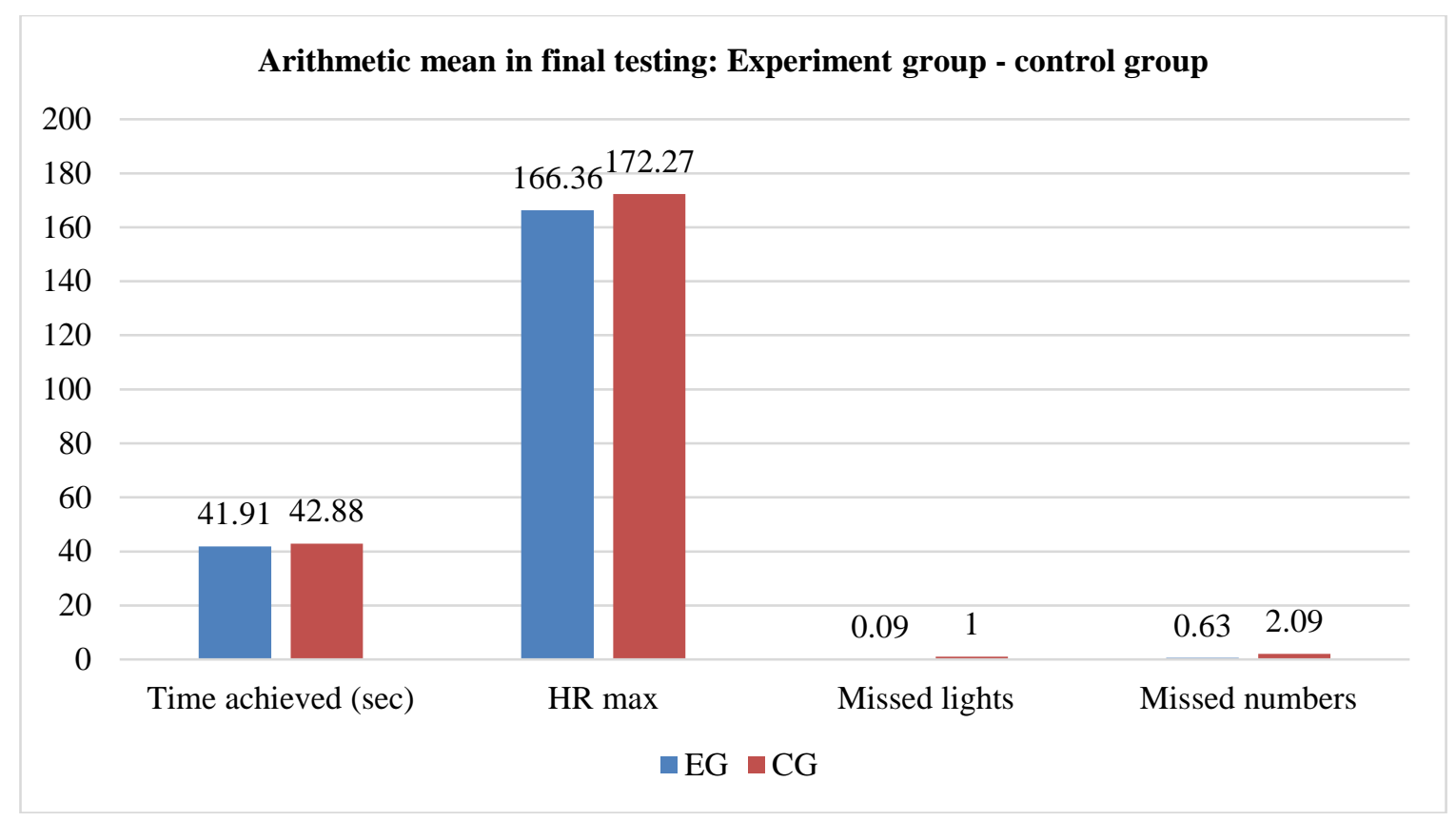

Figure 3. Average results in the final test - Experiment and control groups

\section{Conclusion}

The mean score represented in Figure 3 shows that the experiment group has a lower value of the time achieved, namely $41.91 \mathrm{sec}$, while the control group has a value of $42.88 \mathrm{sec}$.

From the point of view of maximum heart rate, the experiment group has a lower value than the control group (166.36 vs. 172.27), which denotes better adaptation to effort. In the control group, the heart rate did not drop so much because over-stimulation during the match (or training) leads to higher heart rate, poor performance and uninspired decisions.

With regard to the number of LEDs missed in the final test, the value obtained by the experimental group is 0.09 , while the control group has a value of 1 . The missed figures are 0.63 for the experiment group, while the control group get a value of 2.09 .

The results of the research hypothesis that the inclusion of cognitive training in the game of football improves the ability of players to anticipate, inform and evaluate existing situations and play patterns has been confirmed.

\section{References}

Dellal, A. (2008). De l'entraînement à la performance en football [From training to performance in football]. Bruxelles: DeBoeck Supérieur.

Johnson, J. G., \& Raab, M. (2003). Take the first: Option-generation and resulting choices. Organizational Behavior and Human Decision Processes, 91(2), 215-229. https://psycnet.apa.org/doi/10.1016/S07495978(03)00027-X

Lorains, M., Ball, K., \& MacMahon, C. (2013). An above real time training intervention for sport decision making. Psychology of Sport and Exercise, 14(5), 670-674. https://doi.org/10.1016/j.psychsport.2013.05.005

Popa, M. (2008). Statistică pentru psihologie: Teorie și aplicaţii SPSS [Statistics for psychology: Theory and SPSS applications]. Iași: Polirom.

Ward, P., \& Williams, A. M. (2003). Perceptual and cognitive skill development in soccer: The multidimensional nature of expert performance. Journal of Sport \& Exercise Psychology, 25(1), 93-111. https://doi.org/10.1123/jsep.25.1.93 